\title{
Computational Analysis of a Piezo-electrically Actuated Valve-less Micropump for Micro-fluidic Applications
}

\author{
Rohit D. Bankar, Ajay L. Godase, Ashok B. Mule, Nikhil N. Gaikwad, Ranjitsinha R. Gidde
}

\begin{abstract}
Computational analysis of a piezo-electrically actuated valve-less micropump is carried out for microfluidic applications. The effect of the operating parameter frequency on the performance of micropump is studied. The valve-less micropump consists of nozzle/diffuser elements; the pump chamber; a thin membrane (diaphragm) and a piezoelectric disc, PZT 5A of diameter $12 \mathrm{~mm}$ as the actuator. The complete electric-fluid-solidcoupling model is simulated with the commercial finite element analysis software COMSOL Multiphysics 5.0 to investigate the performance of the micropump.
\end{abstract}

Index Terms-Piezoelectic, PZT, Nozzle/Diffuser, Micropump

\section{INTRODUCTION}

A micropump is one of the important devices in microfluidic applications, which can generate flow in the range of milliliters to microliters. A number of potential applications for micropumps are still being investigated, involving in drug delivery,biological detection, clinical analysis in medicine, etc.

A fixed geometry rectification pump, also known as a valve-less micropump is one of the most extensively investigated micropumps, which mainly consists of a flexible membrane propelling the flow and nozzle/diffuser elements for directing the flow. The oscillation of the diaphragm above pump chamber excited by the actuators propels the flow. A micropump requires an actuation mechanism to provide a pressure differential to transfer fluid from one point to another.The common actuation mechanisms include piezoelectric, electrostatic, thermo-pneumatic action, electromagnetic, shape memory alloy etc. Compared with other actuation mechanisms, thepiezoelectric actuation can provide a good reliability andmoderate pressure at low power consumption, which is preferred for medical applications [1]. Andersson et al. [2] designed a valve-less micropump for biological analysis and investigated the dependency on the properties of the pumped biological medium. The absence of

Rohit D. Bankar, Student, Department of Mechanical Engineering, SVERI's College of Engineering, Pandharpur, India

Ajay L. Godase, Student, Department of Mechanical Engineering, SVERI's College of Engineering, Pandharpur, India

Ashok B. Mule, Student, Department of Mechanical Engineering, SVERI's College of Engineering, Pandharpur, India

Nikhil N. Gaikwad, Student, Department of Mechanical Engineering, SVERI's College of Engineering, Pandharpur, India

Ranjitsinha R. Gidde, Associate Professor, Department of Mechanical Engineering, SVERI's College of Engineering, Pandharpur, India moving parts, the simple planar design, and high pump performance in terms of pressure head and flow rate are some of the main advantages of such micropumps.Finite element analysis becomes a very attractive method to model the micro-devices used in microfluidic applications. Earlier studies on micropumps were mostly focused on the simulation of the functional elements, such as the micro-valves and actuators. Meiling Zhu et al. [3] did optimization of the design of geometric parameters of the piezo-electically actuated membrane by using $3 \mathrm{D}$ finite element method (FEM) to maximize piezoelectric actuation capability and ensure actuation reliability.Schalk Willem van der Merwe et al. [4]investigated the characteristics of a planar nozzle/diffuser based micropump using detailedcomputational fluid dynamics (CFD) analyses. Singh et al. [5] analyzed the performances of the nozzle/diffuser elements by using commercial software Fluent.

Therefore, in this study, a three-dimensional finite element modelof the valve-less piezoelectric micropump was built in COMSOL Multiphysics 5.0, including the pump diaphragm, the piezoelectricdisc, and the working fluid and analyzed the effect of constant actuation voltage of $30 \mathrm{~V}$ and thedifferent frequencies on the flow rate.This work, aims to design and study a piezoelectric valve-less micropump for microfluidic applications.

\section{WORKING PRINCIPLE OF A PIEZOELECTRIC MICROPUMP}

The schematic diagram showing the working principle of a piezo-electically actuated micropump is shown in Fig. 1-a and 1-b. A piezoelectric disc is glued with a diaphragm, which forces fluid through a small chamber. So there are basically two main parts of the micropump: a functional layer on which chamber and microchannels are engraved, and a diaphragm which is actuated by a PZT disc. In the supply mode (Fig. 1-a), the outward deflection of the membrane causes the chamber volume to increase, which results in decrease in pressure inside the chamber. In this situation, the fluid flows into the chamber through both inlet and outlet. However, since the kinetic energy of the fluid in the form of velocity is converted to potential energy in the form of the pressure in the diffuser, there is less loss of kinetic energy in the forward direction than in the reverse direction. Thus, the fluid flow from the inlet is greater than the fluid flow from the outlet. Therefore, the fluid is supplied into the chamber from the inlet. In the pump mode (Fig. 1-b), the reduction in the chamber volume creates higher pressure in the chamber. In this case, the fluid flows out from the chamber through both inlet and outlet. However, due to the difference in the loss of the kinetic energy, the fluid flowfrom the outlet is greater than the fluid flow from the inlet $[6,7]$. Thus, the net fluidflow from the inlet to the outlet is achieved. 


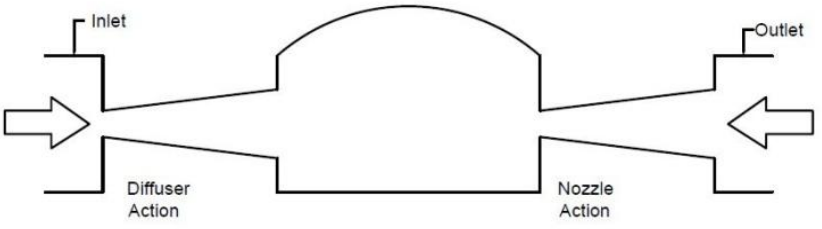

Fig. 1-a. Supply mode

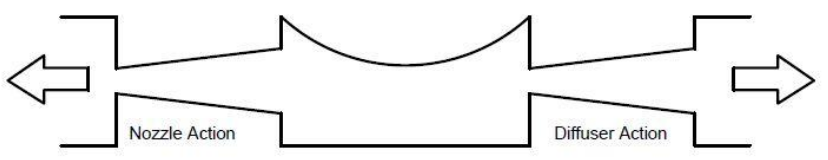

Fig. 1-b. Pump mode

\section{THEORETICAL ANALYSIS}

The performance of a valve-less micropump depends on the properties of the rectification elements (nozzle/diffuser) [8].

\section{Flow rectification efficiency}

The pressure loss coefficient for flows through the nozzle/diffuser element is defined as[9]:

$$
K=\frac{\Delta P}{\rho v^{2} / 2}
$$

Where $\Delta \mathrm{P}$ is the pressure drop across the nozzle/diffuser direction, $\rho$ is the fluid density, and $v$ is the mean velocity of the fluid flow in the nozzle/diffuser elements.

The pressure loss coefficient across the nozzle/diffuser element is the sum of the pressure drops through the three parts, namely, the sudden contraction at the entrance, the sudden expansion at the exit, and the gradual expansion or contractionalong the length of the nozzle/diffuser element. Thus, the pressure loss coefficients across the diffuser direction and the nozzle direction are expressed as:

$$
\begin{aligned}
& K_{d}=K_{d, e n .}+K_{d, l .}+K_{d, e x .}\left(\frac{A_{1}}{A_{2}}\right)^{2} \\
& K_{n}=K_{n, e x .}+\left(K_{n, l}+K_{n, e n .}\right)\left(\frac{A_{1}}{A_{2}}\right)^{2}
\end{aligned}
$$

Where $A_{1}$ is the narrowest cross-sectionarea and $A_{2}$ is the largestcross-section area of the nozzle/diffuser element, respectively.

The diffuser efficiency of the nozzle/diffuser elements is defined as the ratio of the pressure loss coefficient across the nozzle direction to that in the diffuser direction:

$$
\eta=\frac{K_{n}}{K_{d}}
$$

Where, $K_{d}$ and $K_{n}$ are pressure loss coefficients across the diffuser direction and the nozzle direction respectively.If the pressure loss coefficient in the nozzle direction is higher than that in the diffuser direction, i.e., $\eta>1$, a forward flow from the inlet to the outlet is caused. In contrast, $\eta<1$ willlead to a backward flow from the outlet to the inlet.

The flow rectification efficiency of the valve-less micropump is expressed as:

$$
\varepsilon=\frac{Q_{+}-Q_{-}}{Q_{+}+Q_{-}}
$$

Where $\mathrm{Q}_{+}$and $\mathrm{Q}_{-}$are the flow rate in the forward and the backward directions respectively. The flow rectification efficiency reveals the ability of the micropump to generate flow in the forward or backward direction. The higher the $\varepsilon$ is, the better flowrectification in forward direction.

\section{Governing equations}

A piezoelectric disc is utilized as the actuator. PZT-5A, a special type of piezoelectricmaterial, is used in the computational analysis.

The coupled electro-mechanical constitutive equations for the actuator in stress charge form [10] is as given below:

$$
\left.\begin{array}{l}
T=C_{E} . S-e^{t} \cdot E \\
D=e . S-\varepsilon_{S} . E
\end{array}\right\}
$$

Where $\mathrm{T}$ is the mechanical stress tensor, $\mathrm{S}$ is the mechanical strain tensor, $\mathrm{C}_{\mathrm{E}}$ is elastic stiffness constant tensor at constant electric field, $\mathrm{e}^{\mathrm{t}}$ is the piezoelectric constant tensor, Eis the electric field vector, Dis the electric charge displacement vector,eis the piezoelectric coupling coefficient for stress charge form, $\varepsilon_{\mathrm{s}}$ is the electric permittivity.

The polydimethylsiloxane (PDMS)membrane in the piezoelectric valve-less micropump is integrated with surrounding walls; as a result, it can be considered as a clamped plate.

The governing equation of forced vibration of a thin clamped plate[11]can be expressed as:

Where,

$$
D \nabla^{4} W+\rho_{P} \frac{\partial^{2} W}{\partial t^{2}}=f_{e}-P
$$

$$
D=\frac{E t_{m}^{3}}{12\left(1-v^{2}\right)}
$$

Where $D$ is the plate stiffness, $\nabla^{4}$ is the two-dimensional double Laplacian operator, Eis the Elastic modulus, vis the Poisons ratio of the membrane, $t_{m}$ is the thickness of the membrane, and $\rho_{\mathrm{p}}$ is the density of the membrane. $\mathrm{f}_{\mathrm{e}}$ is the periodic actuating force, and $\mathrm{P}$ is the dynamic pressure exerted on the membrane by the liquid.In this case, the pump membrane is assumed to be clamped.

The flow can be considered as an incompressible laminar flow, which can be described using the Navier-Stokes equation (9) and the mass continuity equation (10)[11].

$$
\begin{gathered}
\rho_{L} \frac{D \vec{V}}{D t}=\rho_{L} \vec{g}+\mu \nabla^{2} \vec{V}-\nabla P \\
\frac{\partial \rho_{L}}{\partial t}+(\vec{V} \cdot \nabla) \rho_{L}=0
\end{gathered}
$$

Where, $\rho_{\mathrm{L}}$ is the density of the liquid; $\vec{V}$ is the velocity vector; $\mu$ is the viscosity of the liquid. The boundary conditions for fluid model are no-slip at Fluid-Wall interface and Fluid-Membrane interfaces, and free surface boundary conditions at the inlet/outletof the micropump. 


\section{DESIGN OF MICROPUMP}

\section{Structural design of piezoelectric actuator}

The material used for the construction of piezoelectric transducer requires high reliability, a wide frequency response range, and a linear response to applied voltage with reasonably low cost. In this study, we have used PZT-5A disc with external diameter of $12 \mathrm{~mm}$. The structure of the piezoelectric transduceris shown in Fig. 2. It consists of three elements: a PZT piezoelectric layer, a connecting layer (glue), and a brass disc. A PDMS diaphragm is bonded to this PZT disc. The diaphragm is actuated due to piezoelectric effect induced in the PZT disc. The dimensions of the PZT actuator are shown in Table 1.

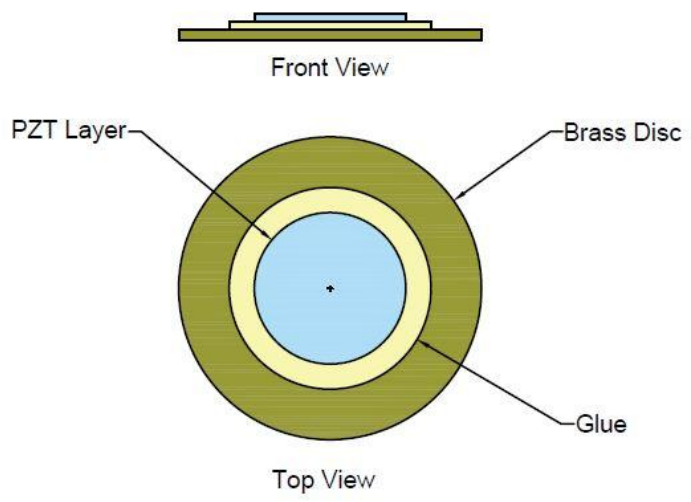

Fig. 2. Structure of piezoelectric transducer

Table 1. Dimension parameters of piezoelectric actuator

\begin{tabular}{clc}
\hline Sr.No. & Parameter & Values $(\mathrm{mm})$ \\
\hline 1. & PZT layer diameter & 7.5 \\
2. & PZT layer thickness & 0.2 \\
3. & Brass disc external diameter & 12 \\
4. & Brass disc thickness & 0.14 \\
5. & PDMS diaphragm diameter & 12 \\
6. & PDMS diaphragm thickness & 0.15 \\
\hline
\end{tabular}

\section{Structural design of functional layer}

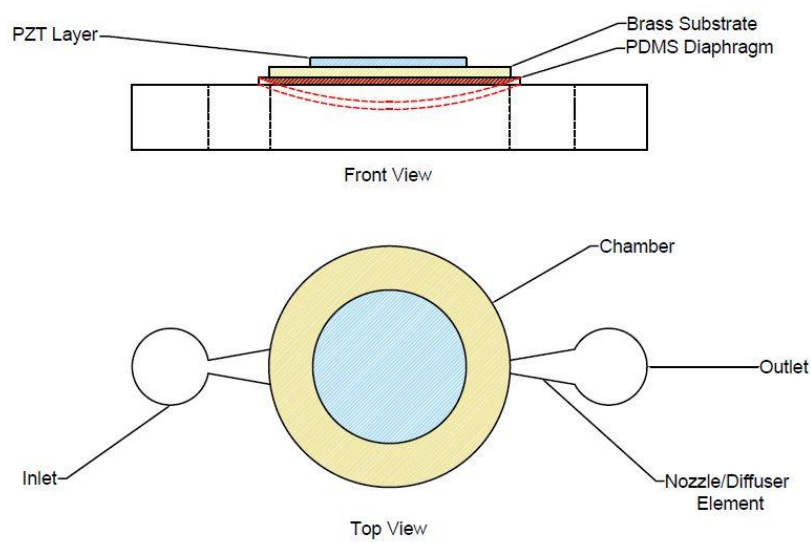

Fig. 3. Schematic diagram of functional layer of micropump

In this study, a valve-less micropump with nozzle/diffuser elements is designed, which utilizes the difference of the flow resistance across the diffuser element and the nozzle element for directing the flow. The functional layer is made of acrylic material which includes two nozzle/diffuser elements, one pump chamber, one inlet chamber and one outlet chamber. The schematic diagram of functional layer is shown in Fig. 3

\subsection{Nozzle/Diffuser element}

The section of microchannel following the direction of the increase of cross-section area is called diffuser, while the section following the direction of decrease of cross-section area is called nozzle. Two nozzle/diffuser elements have the same geometrical dimensions. The diffuser and the nozzleare used as the inlet and outlet of the micropump chamber respectively.

For easy integrating with other MEMS devices and high performance, the planar nozzle/diffuser element is used.At smaller divergence angle, the rectification efficiency is low as both nozzle and diffuser offer the same resistance and thus the net flow rate increases with increase in divergence angle. Similarly, at much higher divergence angles, the flow separation may occur which leads to the reduction in the net flow rate.Therefore, output of micropump also depends on the geometrical dimensions of the nozzle/diffuser element.

Fig. 4 shows the basic dimension parameters of the planar nozzle/diffuser element. These basic dimensions involve the divergence angle $2 \theta$, the channel length $\mathrm{L}$, and the width of the nozzle W1. The values of these dimensions for the proposed micropump are shown in Table 2.

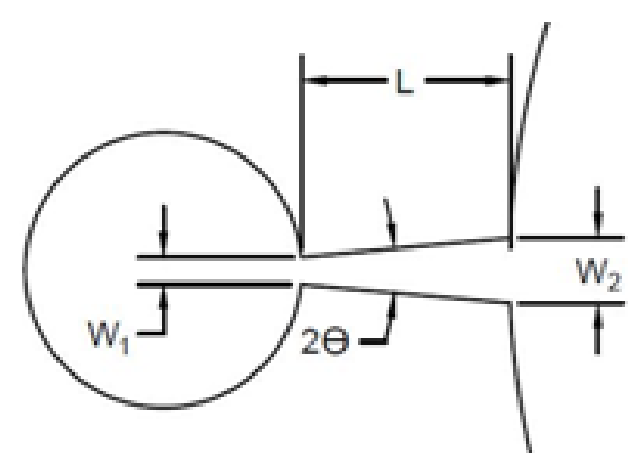

Fig. 4. Schematic diagram of nozzle/diffuser element

Table 2. Dimension parameters of nozzle/diffuser element

\begin{tabular}{clc}
\hline Sr.No. & Dimension parameter & Value \\
\hline 1. & Divergence angle (20) (degree) & 10 \\
2. & Width at nozzle (W1) (micron) & 200 \\
3. & Microchannel length (L1) (mm) & 1.5 \\
\hline
\end{tabular}

\subsection{Pump chamber}

The pump chamber is the central section of the functional layer where fluid gets stored during suction mode and this stored fluid is forced to outlet during discharge mode. The diameter and depth of the chamber should be such that to conform to the diameter and the thickness of the piezoelectric actuator with sufficient space for storing fluid. For this study, we have used functional layer with pump chamber of diameter $12 \mathrm{~mm}$ and depth 500 micron.

\subsection{Inlet and outlet}

The diameters of the inlet and the outlet chambers are to 
conform to the diameters of the inlet and outlet pipes respectively. On functional layer,we have engraved inlet and outlet chambers of diameter $2 \mathrm{~mm}$ each.

\section{COMPUTATIONAL ANALYSES AND RESUlTS}

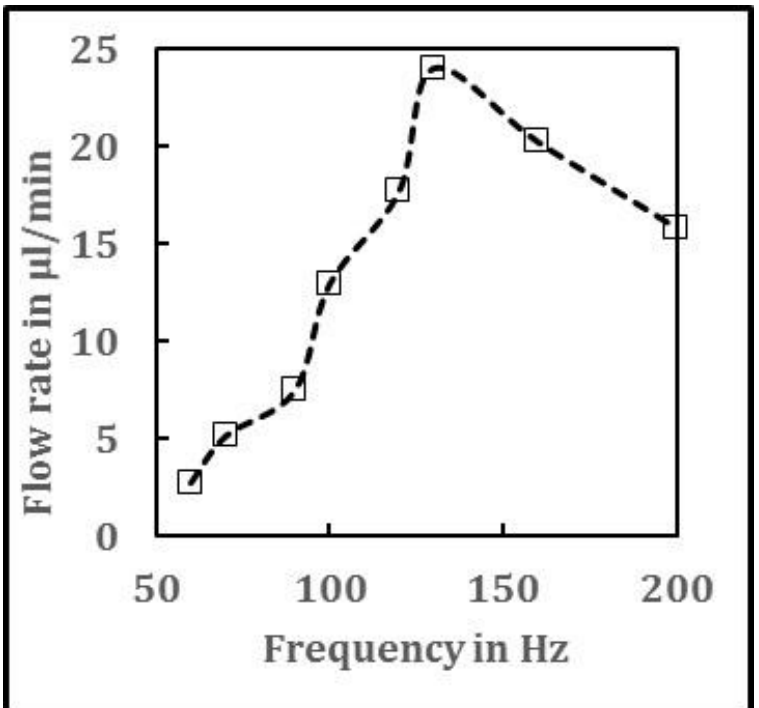

Fig. 5. Flow rate as a function of actuation frequency

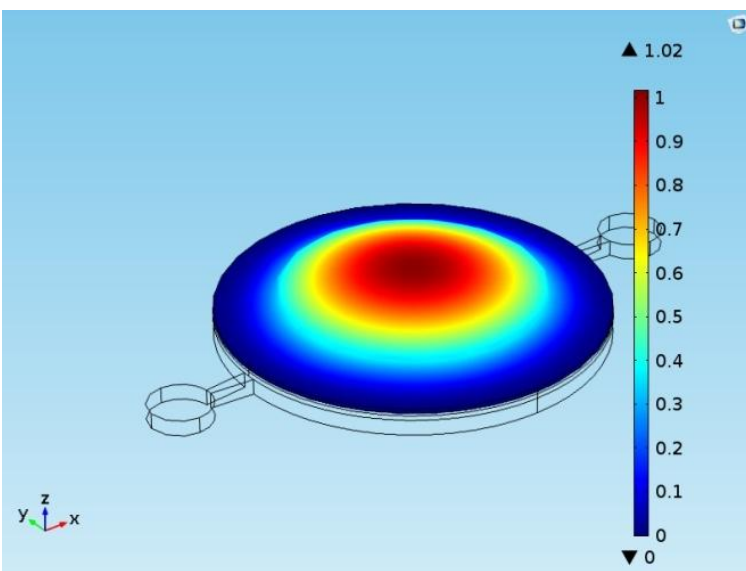

Fig. 6. Total displacement at actuation frequency $130 \mathrm{~Hz}$

The computational analyses are carried out on the proposed micropump design using COMSOL Multiphysics software for the calculation of maximum flow rate at the outlet of the micropump. Water is considered as the working fluid. Also, the total displacement of the PDMS diaphragm is obtained from simulations at the actuation frequency, at which we get the maximum flow rate of discharge.

We have given constant supply of $30 \mathrm{~V}$ AC to the piezoelectric actuator and the actuation frequency is varied from $10 \mathrm{~Hz}$ to $200 \mathrm{~Hz}$. The plot of flow rate as a function of actuation frequency is shown in Fig. 5. The flow rates obtained at frequencies of $60 \mathrm{~Hz}, 100 \mathrm{~Hz}, 130 \mathrm{~Hz}, 160 \mathrm{~Hz}$ and $200 \mathrm{~Hz}$ are $2.77 \mu \mathrm{l} / \mathrm{min}, 12.95 \mu \mathrm{l} / \mathrm{min}, 24.00 \mu \mathrm{l} / \mathrm{min}$, $20.25 \mu \mathrm{l} / \mathrm{min}$ and $15.84 \mu \mathrm{l} / \mathrm{min}$ respectively. The maximum flow rate of $24 \mu \mathrm{l} / \mathrm{min}$ is obtained at outlet of micropump at actuation frequency $130 \mathrm{~Hz}$.

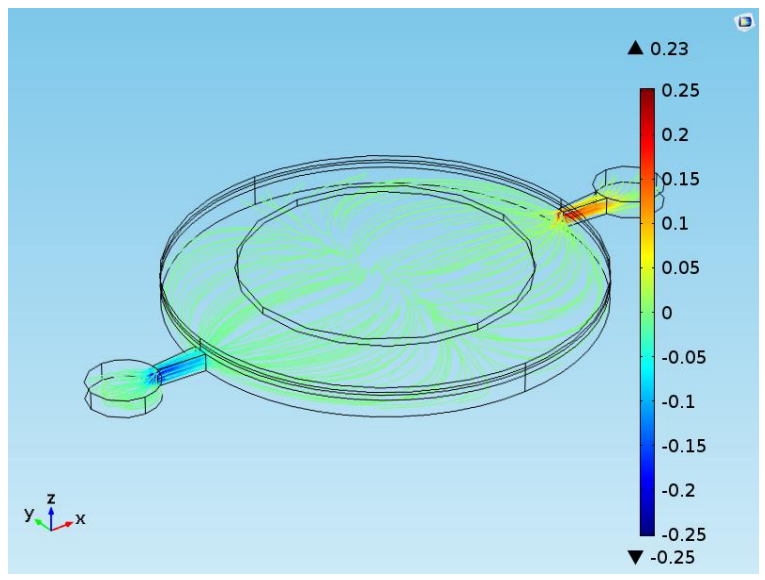

Fig. 7. Streamline velocity distribution inside the pump chamber

Fig. 6 shows the total displacement of the piezoelectric actuator at frequency $130 \mathrm{~Hz}$, where maximum flow rate is obtained. The maximum central displacement obtained at $130 \mathrm{~Hz}$ is $1.02 \mu \mathrm{m}$.

The distribution of streamline velocities inside the pump chamber at $130 \mathrm{~Hz}$ frequency is shown in Fig. 7. From figure, the maximum streamline velocity of $0.23 \mathrm{~m} / \mathrm{sec}$ obtained at the nozzle section of outlet.

\section{CONCLUSIONS}

The working principle of piezoelectric micropump has been studied and the micropump is designed for piezoelectric disc of $12 \mathrm{~mm}$ diameter. The driving parameters of the piezoelectric transducer have been determined and their effects on flow rate of micropump, displacement of actuator and streamline velocities are investigated using computational analyses. The results of computational analyses can be summarized as below:

1.The maximum flow rate at the outlet of micropump at 30 $\mathrm{V}$ supply is obtained at $130 \mathrm{~Hz}$ frequency. The maximum flow rate obtained is $24 \mu \mathrm{l} / \mathrm{min}$.

2. The maximum central displacement of piezoelectric actuator at $30 \mathrm{~V}$ voltage and $130 \mathrm{~Hz}$ frequency is $1.02 \mu \mathrm{m}$.

3 . The maximum streamline velocity is $0.23 \mathrm{~m} / \mathrm{sec}$ for 30 $\mathrm{V}$ at $130 \mathrm{~Hz}$ supply condition.

\section{REFERENCES}

[1] Gidde, R.R. and Pawar, P.M., 2017. On effect of viscoelastic characteristics of polymers on performance of micropump. Advances in Mechanical Engineering, 9(2), p.1687814017691211. Andersson, H., Van Der Wijngaart, W., Nilsson, P., Enoksson, P. and Stemme, G., 2001. A valve-less diffuser micropump for microfluidic analytical systems. Sensors and Actuators B: Chemical, 72(3), pp.259-265.W.-K Chen, Linear Networks and Systems (Book style). Belmont, CA: Wadsworth, 1993, pp. 123-135.

[2] Andersson, H., Van Der Wijngaart, W., Nilsson, P., Enoksson, P. and Stemme, G., 2001. A valve-less diffuser micropump for microfluidic analytical systems. Sensors and Actuators B: Chemical, 72(3), pp. 259-265

[3] Zhu, M., Kirby, P., Wacklerle, M., Herz, M. and Richter, M., 2009. Optimization design of multi-material micropump using finite element method. Sensors and Actuators A: Physical, 149(1), pp.130-135.

[4] Van der Merwe, S.W., 2010. A MEMS based valveless micropump for biomedical applications (Doctoral dissertation, Stellenbosch: University of Stellenbosch).

[5] Singh, S., Kumar, N., George, D. and Sen, A.K., 2015. Analytical modeling, simulations and experimental studies of a PZT actuated 
planar valveless PDMS micropump. Sensors and Actuators A: Physical, 225, pp.81-94.

[6] Gidde, R.R., Pawar, P.M., Ronge, B.P. and Dhamgaye, V.P., 2019 Design optimization of an electromagnetic actuation based valveless micropump for drug delivery application. Microsystem Technologies, 25(2), pp.509-519.

[7] Pawar, P.M., Gidde, R.R. and Ronge, B.P., 2016, December. Shape optimization of microfluidic pump using fluid-structure interaction approach. In Techno-Societal 2016, International Conference on Advanced Technologies for Societal Applications (pp. 471-477). Springer, Cham.

[8] Singhal, V., Garimella, S.V. and Murthy, J.Y., 2004. Low Reynolds number flow through nozzle-diffuser elements in valveless micropumps. Sensors and Actuators A: Physical, 113(2), pp.226-235.

[9] Cui, Q., Liu, C. and Zha, X.F., 2008. Simulation and optimization of a piezoelectric micropump for medical applications. The International Journal of Advanced Manufacturing Technology, 36(5-6), pp.516-524.

[10] Dosch, J.J., Inman, D.J. and Garcia, E., 1992. A self-sensing piezoelectric actuator for collocated control. Journal of Intelligent material systems and Structures, 3(1), pp.166-185.

[11] Fan, B., Song, G. and Hussain, F., 2005. Simulation of a piezoelectrically actuated valveless micropump. Smart materials and structures, 14(2), p.400. 